IRA-International Journal of Applied Sciences ISSN 2455-4499; Vol.07, Issue 01 (2017)

Institute of Research Advances

Pg. no. 6-33

https://research-advances.org/index.php/IRAJAS

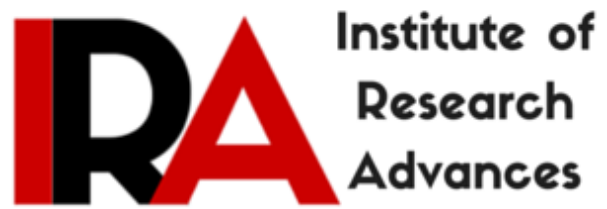

\title{
Rapid Tests for Detection of Main Clostridial Toxins
}

\author{
Pérez-Etcheverry Diana ${ }^{1}$ and Lorenzo-Ferreiro Carmen ${ }^{2}$ \\ ${ }^{1,2}$ Laboratorio de Biotecnología del Instituto Polo Tecnológico de Pando - Facultad de \\ Química, Universidad de la República. Canelones, Uruguay.
}

Type of Review: Peer Reviewed.

DOI: http://dx.doi.org/10.21013/jas.v7.n1.p2

\section{How to cite this paper:}

Diana, P., \& Carmen, L. (2017). Rapid Tests for Detection of Main Clostridial Toxins. IRAInternational Journal of Applied Sciences (ISSN 2455-4499), 7(1), 6-33. doi:http://dx.doi.org/10.21013/jas.v7.n1.p2

(C) Institute of Research Advances

\section{(cc) EY-NC}

This work is licensed under a Creative Commons Attribution-Non Commercial 4.0 International License subject to proper citation to the publication source of the work.

Disclaimer: The scholarly papers as reviewed and published by the Institute of Research Advances (IRA) are the views and opinions of their respective authors and are not the views or opinions of the IRA. The IRA disclaims of any harm or loss caused due to the published content to any party. 


\section{ABSTRACT}

The genus Clostridium is ubiquitous[1], because of this they find easily their way into wounds, foods and feeds, being the cause of serious illness on human and domestic animals. Manifestations and pathology can range from mild food poisoning to death [2-13]. Outstanding to their high toxicity, and the rapid evolution of infection with serious consequences [14-19], it is important to detect it rapidly. One approach is to have rapid detection tests to major clostridial toxins in complex matrices (blood, culture media, food and others), that can be implemented in point of care centers.

In this review, a survey of recent work is carried out in this line of research and development.

Keywords: Clostridium toxins, rapid test

\section{Introduction}

The genus Clostridium (C.) comprises a number of spore forming Gram positive, rod shaped bacilli. They are widely distributed in the soil as well as in marine and freshwater sediments and can also be found in the intestine of numerous mammalian species including human and his domestic animals[1]. Both human and domestic animals suffer from clostridial infections. Because of their ubiquity, Clostridia find easily their way into wounds, foods and feeds, being the cause of serious illness, usually (if not always) mediated by their toxins. Manifestations and pathology can range from mild food poisoning to the most serious necrotic enteritis [2-12]. Some of the diseases include gas gangrene, clostridial enterotoxemia, tetanus and botulism, which are widespread and are cause of serious human lives[6, 13] and economic losses[14-16].

Due to their high toxicity, stability and high diffusivity, clostridial toxins, are of significant importance not only as zoonosis agent [17] but also as food poisoning agents[18] and potential biological weapons[19-22]. Very frequently, the effects on individuals are less severe if in the early hours a precise detection enables appropriate medical treatment [23, 24].

For this reason, it is valuable to develop rapid detection tests to major clostridial toxins considering all complex matrices wherever it can be located (blood, culture media, food and others). Currently, a wide variety of techniques for detecting Clostridia can be found, namely molecular methods as PCR (variations of the PCR technique)[25-29], biochemical techniques [16, 30, 31] search for markers of inflammation[3], in vivo tests and others[16, 32, 33]. Nevertheless the continue research in this issue still remains of interest. The motivation of improvement of assay development tend to accomplish two main aims, on one side replace the mouse bioassays with in vitro assays with sufficiently low limits of detection and on the other hand to develop rapid assays as sensitive as possible, requiring few hours to get the result. In this paper we will focus on the review of in vitro techniques presented so far in which clostridial toxins are directly detected in different matrices.

\section{Botulinum TOXINS}

Botulinum neurotoxins (BoNTs) produced by $\mathrm{C}$. botulinum are the most poisonous toxins known in nature, and have been classified as a category A agent by the Center for Disease Control and Prevention in the United States (https://www.cdc.gov/) [22].

Within C. botulinum species, microorganisms of different characteristics and expressing different toxin types can be found. Seven serologically different BoNTs have been identified and designated as A to G [34]. They are classified in groups, Group I-IV organize the variable bacterial traits within the species (within different Groups could express the same toxin type and a single Group could express different toxin types). Two additional Groups were identified; Group V which includes the BoNT/F producing C. baratii strains[35] and Group VI which represents the BoNT/E producing C. butyricum strains[36]. Food 
borne botulism results from the absorption of toxins A, B, E, and F. Type A toxin is usually associated with more severe disease and a higher mortality rate than types B or E. Type A toxin is typically found in home preserved and canned foods that had not been heated to the accurate temperature. The lethal dose of aerosol forms of BoNT/A is $0.07 \mu \mathrm{g} / \mathrm{kg}$ of body weight $[19,20], 0.001 \mu \mathrm{g} / \mathrm{kg}$ by injection, or $1 \mu \mathrm{g} / \mathrm{kg}$ orally form[23].

Home preserved vegetables, fish, and meat are recognised sources of infection Type E toxin[37].

Therapy for botulism consists of supportive care and administration of equine antitoxin serum. Equine antitoxin cannot reverse the existent paralysis, but acts by neutralizing the toxin when it is gone from the cell. For that reason, timely diagnosis of botulism is critical, for the neutralizing antibodies be effective. The diagnosis of botulism based on the clinical symptoms cannot meet the clinical need, thus the development of rapid laboratory tests for botulism is an important public health issue[38].

At present, the standard reference test for detecting BoNTs is the LD50 test in mice [39], which allows detecting BoNTs at concentrations as low as $5-10 \mathrm{pg} / \mathrm{ml}$ but it takes 4 days to complete[40, 41]. This method is labour-intensive, time-consuming and although variations of the same exist already[4245], requires sacrificing numerous animals to perform the assay, which severely limits the number of samples that can be assayed. Furthermore, the LD50 test has not been standardized, so the potency units are not equivalent between different BoNT products[46]. Therefore, the creation of sensitive detection methods to monitor low levels of BoNTs is essential. In this line, several methods for rapid detection of BoNT have been designed, namely ELISA and different variations of the same[40, 47-55], immunochromatography[21, 52, 56-58], electrochemiluminescence[47, 59, 60], activity assay[31, 41, 6064], mass spectrometry[65-68], Bead-based methods[59, 69-72], Cell-Based Assays[64, 73-76], Biosensor[75, 77-84].

Due to the wide variability of methods that have been developed for detection, quantification of BoNT, one way to simplify this information is to group them as proposed Dorner et.al. [85]

1- Immunological assays (detecting the presence of the Toxin).

2- In vitro biochemical methods (detecting the catalytic activity and the serotype)

3- Functional (Measure the full biological activity and toxicity)

Previously, a few articles reviewed widely assays for BoNT detection, quantification in different matrices (foods, biological samples) until 2015 [57, 70, 85-89]. In this chapter, we will focus on to the most latest methods developed for BoNT, including works from 2016.

One of the features mostly used for analytical detection of BoNT is the proteolytic function of the BoNT light chain[90]. Colorimetric, fluorimetric and luminescence methods were developed[91-94], however these did not show a suitable limit of detection or if they did, the need of specialized equipment, make them unsuitable for point-of-care applications. Shan Chen et. al. [95] developed a new and easy to use colorimetric detection of functional BoNT mediated by gold nanoparticles agglomeration. This work is based on the ability of active BoNT to enzymatically cleave SNAptide ${ }^{\circledR}$, a synthetic peptide that acts as substrate. Cleaved peptides induce the agglomeration of gold nanoparticles, and then changes in the solution color can be detected. For this purpose SNAptide was modified by introducing biotin at one end and cysteine on the other termini. When BoNT is present, modified SNAptide is enzymatically cleaved by the toxin. Then the fragments with the biotin end are removed using magnetic microparticles containing streptavidine and gold nanoparticles are added to bind the cleaved peptide with a cysteine end, afterwards $\mathrm{Cu} 2+$ is added. The $\mathrm{Cu} 2+$ has a strong affinity to the amine groups on the peptide fragments, the peptide act as a bridge to numerous gold nanoparticles-peptide fragments, leading to the agglomeration of gold nanoparticles, leading to color change. In the case BoNT is absent; the gold nanoparticles continue monodispersed after all modified SNAPtide are removed with magnetic streptavidin microparticles. 
A colorimetric signal can be discerned by the naked eye at a concentration of $1 \mathrm{ng} / \mathrm{mL}$, the limit of detection can be improved by measuring the spectral absorbance of the resulting suspension, to a 0.25 $\mathrm{ng} / \mathrm{mL}$.

This method for detection of the active BoNT has the advantage of being fast, simple, of not requiring sophisticated equipment and having a low limit of detection, as to be implemented in health centers of low resources. What if required would be more interference studies of the matrix.

Emina Wild et. al [96] describe a combined in vitro assay for the detection of active BoNT /B, it takes into account the binding as well as the protease function of the toxin, in that way measuring its biological activity. Its development is mainly intended to determine the potency of said toxin, in the products thereof, with cosmetic application, which is usually accomplished by performing LD50 test in mice. They are describing an interesting alternative in vitro assay for the potency determination of the BoNT / B, reaching a detection limit below 0.1 mouse $\mathrm{LD} 50 / \mathrm{ml}$.

In this assay of the BoNT/B binding and cleavage, the toxin is primary bound to its specific receptor previously immobilized in a well plate. Following, the proteolytic subunit of the toxin is activated by chemical reduction of the inter-chain disulfide bond, the L-chain is recovered from the supernatant and transferred to a plate coated with synaptobrevin (specific substrate of the L-chain) and incubated to allow the cleavage reaction. After washing steps, the proteolytic cleavage is quantified by an antibody-mediated detection of the neoepitope.

This technique would be useful to replace the LD50 assay, since the authors shown that it is at least equally sensitive or even lower and in turn specifically detect only active BoNT molecules. As a comparative advantage is robust and easy to standardize.

It is very important to note that the method described above covers the two most significant toxin functions by evaluating the integrity of the binding domain as well as the proteolytic activity.

Other assays for the detection of active BoNTs only evaluate one of the functions of the toxins (proteolytic activity)[67, 97] but are not sufficient to reliably discriminate therapeutically active from inactive BoNT molecules.

As the authors express to promote the inclusion of the method in the European Pharmacopoeia would lack validation studies.

Immunological methods, has been extensively used to detect BoNTs, however they often present interference from the matrix, and may give false positives[98]. Accordingly, electrochemical biosensors are real alternative for BoNTs detection, having the characteristics of simplicity, momentum, high sensitivity, and lower costs.

Abbas Afkhami et. al. [99] developed an impedimetric immunosensor for a rapid and sensitive immunoassay of BoNT/A, with a detection limit of $0.11 \mathrm{pg} / \mathrm{mL}$. They use a carbon electrode with Au nanoparticles/graphene-chitosan for signal amplification, with anti-BoNT/A antibodies immobilized. To detect BoNT/A, they employ the impedance changes, generated by the specific immuno-interactions at the immunosensor surface. They further determined that the measurements were highly specific and have a linear correlation with BoNT/A concentrations in different matrix (PBS, milk and human serum).

This immunosensor showed a good sensitivity, a low detection limit, reproducibility, storage stability and low cost compared to other sensors[99], which would allow its implementation in the market.

In the past years, significant progress has been made in the detection of BoNTs primarily because their clinical importance and their potential use in bioterrorism. There is a vital need for rapid in vitro diagnostics that can be validated to replace the mouse bioassay, currently there are no in vitro method that can play that role.

To the clinical need, the detection time must be much less than the mouse bioassay, and with a limit of detection equal to or less than this technique. Today several developments to BoNT detection were based on a combination of methods; immunological; functional methods; biochemical methods. These not only 
contemplate absence and presence, but functionability and in some cases potency, which makes them possible candidate to replace the mouse bioassay, but should have a strong validation against it.

\section{C. difficile TOXINS}

Clostridium difficile is the leading cause of hospital diarrhea in developed countries and an increasingly common etiology of community diarrhea. In several cases cause pseudomembranous colitis and even death[100]. Even though, the major risk factors in patients are the past of antibiotic treatment, an age of over 65 years, and prolonged hospitalization.

Toxigenic strains of $\mathrm{C}$. difficile produce the toxin A and B exotoxins that mainly cause the symptoms of Infection C. difficile. In addition, some strains produce the binary toxin, whose role in the pathogenesis is not yet very clear[101-103].

The reference method for the detection of C. difficile is cytotoxicity of stool in cell culture, is recognized as the most sensitive method for detection of C. difficile, but its specificity is low, it does not distinguish between toxigenic and non-toxigenic isolates and requires $24-48 \mathrm{~h}$ to obtain the first results [104]. Therefore, stool culture testing can be coupled with a cell cytotoxicity assay or EIA (enzyme immunoassay) to detect toxins producing C. difficile strains [105], resulting in increased specificity[106]. Detection techniques for toxins A and/or B using EIA are quick[105, 107], simple and low cost; low sensitivity and not enough good specificity dismiss them as infection C. difficile diagnostic. The sensitivity and specificity of EIAs ranged from $32 \%$ to $83 \%$ and from $84 \%$ to $100 \%$, respectively[107110]. Therefore, the overall poor performance of toxin EIAs led to the recommendation to use them only as a part of a two- or three-stage algorithm[3, 104].

The main disadvantage of these techniques is their lack of sensitivity, when compared to the toxigenic culture. The behavior of these techniques can lead to a large number of false positives and false negatives. False positives may lead to unnecessary treatment of C. difficile infection, withdrawal of other antibiotics, and inadequate isolation of the patient who may sometimes share a room with a true case of $\mathrm{C}$. difficile infection. On the other hand, false negatives may prevent patient from treatment and favor the dissemination of the pathogen in the hospital environment $[110,111]$.

As alternative the detection of the enzyme glutamate-dehydrogenase (GDH) could be a good choice, this protein is produced constitutionally and in large quantities by most strains of C. difficile. The sensitivity of detection is high, with values close to $90 \%$ when compared to the toxigenic culture, however, it has a positively low specificity and predictive value because it detects both, producing and non-producing toxin strains[110, 112].

So far there, are several reviews of the molecular methods developed to detect C. difficile toxins, and their use for diagnosis[100, 107, 110, 111, 113-115].

In the last two years, some immunoassays have been developed [116-119] that can overcome the stagnation of $\mathrm{C}$. difficile toxin detection. These methods, are in many cases simples, fast and ultrasensitive, and have a large potential for clinical applications in the future.

An example is the Yi-Wei Tang et al.[120] real-time cellular analysis for detection a functional toxin B. The cells were cultured in microelectrode and were monitored by changes in electrode impedance. Toxin cause cytotoxic effects on the cells and this resultes in decrease of the electronic impedance, reflecting the cell number, cell morphology, and cell adhesion degree. This technique had a specificity of $99.6 \%$ and a sensitivity of $87.5 \%$ (28 of 32), which is higher than the EIA result. When a pre-step of immunomagnetic separation enrichment process is added, in which toxin B is first captured from supernatant via magnetic beads[116], the specificity raises to $99.7 \%$. 
Other example is the ELISA developed by Linan Song et. al.[117], an ultrasensitive toxin detection based on single molecule array technology. This assay was validated using culture filtrates prepared from a panel of clinical C. difficile strains and adult clinical stool specimens. The detection limit reported is $0.45 \mathrm{pg} / \mathrm{mL}$ for toxin $\mathrm{A}$ and $1.50 \mathrm{pg} / \mathrm{mL}$ and for toxin $\mathrm{B}$.

Despite the evident progress in the development of different rapid diagnostic techniques over the past decades, in terms of $\mathrm{C}$. difficile infection, for the moment no cost-effective rapid diagnosis tests are available.

There have been many advances in the understanding of the pathogenic ways and mechanisms with the host interactions at molecular level of C. difficile[100, 103, 121], but still a transcendental question continue to arise, whether the fecal presence of this organism equates to disease.

\section{Novyi TOXINS}

Alpha-toxin from C. novyi is part of the family of large clostridial cytotoxins that also include toxin $\mathrm{A}$ and toxin $\mathrm{B}$ of Clostridium difficile, and the hemorrhagic and the lethal toxin of Clostridium sordellii [122].

Clostridium novyi is classified into A, B, C, and D, according to the respective soluble antigens. Only types $\mathrm{A}$ and $\mathrm{B}$ synthesize the lethal alpha-toxin[123], type $\mathrm{A}$ is implicated in gas gangrene infections in man and animals $[124,125]$ and type B is the cause of black disease in sheep and other animals[126] both causing important economic losses. In addition, illicit substances users are under risk of infection with clostridium species by injection, which can cause gas gangrene, leading to severe illness or death[124, 125, 127-129].

Particularly, for C. novyi, there are two possible scenarios in which rapid tests are required for the detection of alpha toxin; 1) In monitoring the production of toxin in industrial reactors for vaccine fromulation and 2) for rapid diagnosis in health care centers.

1) In cattle the way to prevent this disease is vaccination, employing vaccines produced with toxoids or with toxoids and bacterins[17, 130-132].

The standardization of culture in industrial reactors is complex, since the release of toxin into the medium is quite erratic between batches, starting and reaching its peak at different times[130, 133]. At present, toxin concentration is measured by using in vivo methods by means of experimental animals, which have clear drawbacks. On one hand, they need to use a lot of animals and on the other hand the results are provided only $72 \mathrm{~h}$ after sampling[134], at that time the state of the culture could have changed, coming to have degradation of the toxin.

An ELISA has been developed for the purpose of monitoring the release of toxin into the culture medium and/or for use in the measurement of toxoid in the final preparation[135], with a detection limit of $1 \mathrm{ng} / \mathrm{mL} \mathrm{ng} / \mathrm{ml}$ toxin.

This technique is laborious to implode for the measurement of toxin levels in the reactor, since in total between the washes and antibodies incubation, it would take more than $1 \mathrm{~h}$ its realization, if it is an excellent technique to quantify the toxoid, since it has a low limit of detection.

In our laboratory we had prepared a latex agglutination reagent rapid test for detecting alphatoxin of C. novyi B for use in Veterinary Vaccine Industry, showing a detection limit of $4 \mu \mathrm{g} / \mathrm{mL}[133]$. This reagent is successfully used in the company to monitor toxin production in industrial reactors, since the operator can make an informed decision to stop the process in just $5 \mathrm{~min}$. This method has several advantages compared to current in vivo method, first it does not use animals, does not require 
sophisticated equipment or highly skilled personnel, results are available in only $5 \mathrm{~min}$, the titration curve of toxin is provided in real time wich allows to the operator to make an informed decision to stop the process.

According to the European Pharmacopoeia[136] the potency testing of C. novyi (type B) vaccines for veterinary use, requires inoculation of laboratory rabbits followed by toxin neutralization test in mice.

Erika Borrmann et al.[137] based on the ability of the $\alpha$ toxin to produce cytopathic effect [138140], evaluated whether it is possible to replace the animal test with a cell assay.

They demonstrate that the three cell lines tested (ESH-L cells, Vero cells, SFT-R cells) are suitable indicators of toxicity of C. novyi B $\alpha$ toxin in the toxin neutralization test, and that on the three cell lines the results are reproducibly. These results are the preliminary point for the progress of the neutralization test using cell cultures.

2) No rapid test for detection of C. novyi $\alpha$ toxin in health centers is currently available, diagnostic is based on culture and observing cytopathic effect in different cell lines[125, 127].

The incidence of C. novyi infections in humans is relatively low, but on the other hand this infection has a mortality rate around $50 \%[125,127,129]$. Because of this high mortality, this concern of having rapid and sensitive tests should be on the research and development schedule of the scientific community

\section{Sordellii TOXINS}

Clostridium sordellii cause enteritis and enterotoxemia in cattle[141] and sheep [142-144] and myonecrosis [145] and gangrene in humans [5, 146]. Gynecological infections in human after childbirth and abortion[147-150], post-operative infections[4], and necrotizing soft tissue infections associated with heroin use $[4,151]$ can be attributable to infection with C. sordellii. Two toxins are a main responsible virulence factors of C. sordellii: hemorrhagic toxin (TcsH) and lethal toxin (TcsL)[152-155].

The mortality rate for patients with C. sordellii infection is 40-69\%, and most patients die within days or even hours after the initial presentation[4]. For that reason, premature diagnosis of C. sordellii infection is of main importance; the low prevalence of the illness and the fact that the initial symptoms are nonspecific make a precise diagnosis very difficult. The time lapse between the beginning of symptoms and death is frequently so short that does not allow to initiate an empirical antimicrobial therapy.

Currently, the C. sordellii diagnostic is determined by means of anaerobic cultures of blood, which is not only time consuming but also is limited to certain laboratory facilities that not all hospital laboratories have, thus do not perform antimicrobial testing on anaerobes.

All this, demonstrates the need to research and develop molecular techniques to rapidly detect and identify C. sordelli infection, and one possibility is to diagnose through the presence of its toxins.

Resembling C. novyi, this infection can be controlled with vaccination[154] in animals, in the production of the toxins at the industrial level, the same problems occur (used later in the formulation of the vaccine). For this reason in our laboratory we had prepared a latex agglutination reagent rapid test for detecting TcsL-toxin of C. sordelli[156].

The latex reagent for $\mathrm{C}$. sordellii lethal toxin presented a detection limit $8 \mathrm{ng} / \mathrm{mL}$, specificity was analyzed by testing cross-reactivity with cultures of C. novyi B,C. septicum, C. tetani, C. botulinum types $\mathrm{C}$ and $\mathrm{D}, \mathrm{C}$. perfringens $\mathrm{C}$, and C. perfringens $\mathrm{D}$. No agglutination was observed in any of them[156]. The methods described herein are rapid and inexpensive, they may be used next to the reactor, provide immediate results, do not require sophisticated equipment or skilled personnel, and are consistent with the trend to reduce, refine, and replace animal use[157]. 


\section{Tetani TOXINS}

C. tetani is classified into 10 serological types (types I to $\mathrm{X}$ ) based on agglutination. All strains produce the same toxin, tetanus toxin, a $150 \mathrm{kDa}$ protein[158], which binds to the nerve centers and causes muscular contractions. This can be fatal by blocking the respiratory muscles[159].

Tetanus is totally preventable by active immunization. Since the disease does not give immunity to whoever suffers it, vaccination is the first support to avoid clinics manifestations, or at least, decrease the severity of these[160].

Even though less common in the developed world, it is a important infection in developing countries, where mortality remains high[161]. Although the implementation of immunization programs, a large number of cases have been reported from the developing world[162-165], being the most common cause of otogenic tetanus the trauma followed by lesion contamination[166]. In developed countries, it has been observed that tetanus infections occur in immunosuppressed patients, diabetics, the elderly who were not vaccinated in their childhood, and patients older than 50 years with serological tests with low levels of antibodies against tetanus toxin[167, 168]. For this reason nowadays many efforts are focused on improving techniques for measuring antibodies against this toxin[169-172] and in the development tetanus neurotoxin neutralizing antibodies[171, 173, 174].

Clinically diagnosis, it is counted with the spatula test, this is the most useful and a simple bedside diagnostic test for tetanus, being $100 \%$ specific and $94 \%$ sensitive. Laboratory diagnosis of tetanus infection is carried out only to confirm the clinical diagnosis. Mainly, it is based on the culture of the samples using the appropriate culture media, this method is positive in only $30 \%$ of cases of tetanus, because many organisms are killed when exposed to air during sampling process. At the laboratory level, it can also be performed the toxigenicity test, in vitro neutralization test on blood agar or in vivo neutralization test in mice[158, 175]. Unlike other Clostridium, there is not a great call for novel diagnosis methods that would encourage the development of new techniques.

Vaccines have played a definite role in the success of global immunization programmes. Regarding the vaccine manufacture, the stability of the vaccine during production, storage and transport is a major concern. The losses of the potency as well as the confirmation of absence of residual toxicity are the main aspects subjected to control. At different batches the variation is common[176], so that quality control of various batches is thus a central issue.

In case of tetanus toxoid, a standard method of analysis for testing the antigenic purity is ELISA[177, 178]. Harshvardhan B. Modh et al. [179] replaced the antibodies in the conventional ELISA for the detection of tetanus toxoid by using an aptamer. The aptamer-based assay (ALISA) was able to detect 1ng of tetanus toxoid, which was the same as with ELISA. The aptamer, show high affinity, are easier to handle and manipulate since they are synthesized in vitro.

The elimination of residual toxicity in each batch of tetanus toxoid is subject to strict safety testing. Currently the safety tests have to be performed following in vivo toxicity tests in guinea pigs[180]. However, a replacement by an in vitro method would be desirable. Heike A. BehrensdorfNicol et al.[30, 181] developed a method which detects active tetanus neurotoxin based on their proteolytic activity and specific receptor-binding capacity (BINACLE assay). For the BINACLE assay tetanus neurotoxin is bound to immobilized ganglioside GT1 reduced to liberate and activate the Lchains, then is transferred to a plate containing recombinant synaptobrevin-2, this is cleaved by active Lchains, and the fragment is detected. The tetanus neurotoxin only generates a signal if they have intact binding and protease domains, and if both domains can be separated by reduction, this is equivalent to the in vivo test. The detection limit of the BINACLE assay for pure TeNT is $0.03 \mathrm{ng} / \mathrm{ml}$, Being more sensitivity than the animal test $(0.1 \mathrm{ng} / \mathrm{ml})$. 
This technique that combines binding and cleavage functions, it more consistently to discriminate between toxic and detoxified molecules than other in vitro assays, which detect one a single toxin function (e.g. endopeptidase assays[182]).

\section{C. perfringens TOXINS}

C. perfringens is classified into 5 types (A-E) depending whether they produce one or more of the major toxins: alpha, beta, epsilon, and iota, which have lethal, necrotic and cytotoxic activities[183]. All types produce alpha toxin, besides alpha toxin, type B produce beta and epsilon toxins, type C produce beta toxin, type $\mathrm{D}$ epsilon and type $\mathrm{E}$, iota. Also recently identified a binary enterotoxin of $\mathrm{C}$. perfringens, as the novel virulence factor cause of a gastroenteritis[184]. C. perfringens is the most important Clostridium species causing gas gangrene[185, 186], and is related to variety of infectious disease: myonecrosis in humans and animals (A strains); lamb dysentery (B strains); necrotizing enterocolitis (C strains); enterotoxemia of sheep (D strains), and are the cause of enterotoxemia in calves and lambs (E strains)[187-195].

Infection caused by Clostridium perfringens is assumed only after physical exam and in relational to history of the patient[196]. Laboratory diagnosis of C. perfringens can be done by bacteriologic culture as well as by detecting a bacterial toxin [197-200]. Nowadays genetic methods are available and allow a rapid much typing of C. perfringens[201-204]. These techniques are precise and quick; but only suggest a gene's existence, and can assure neither a present nor an active toxin that could be responsible of physical damage. This is a problem taking into account that the microorganism is ubiquitous and can be present in on soil, water as well as the gastrointestinal tracts of various mammals, including humans[205], one alternative is de real time PCR[206].

As mentioned above, all subtypes of $\mathrm{C}$. perfringens produce the alpha toxin, which makes it the clear target for assay development for clinical use[188]. Alpha toxin has been linked to human and other animal sudden infant death syndrome and numerous human deaths related to food poisoning by type A[207-209]. Since premature diagnosis and harsh treatment are the solution to decreasing morbidity and mortality, development of a rapid sensitive assay for detect and measure C. perfringens alpha toxin is necessary.

Numerous methods are available for detection, quantification of C. perfringens alpha toxin as mouse lethality assays, Dot-ELISA, ELISA and PLC enzymatic activity, these techniques do not have satisfactory low detection limits $(19-130 \mathrm{ng} / \mathrm{ml})[10,210-215]$. Other authors have developed a rapid electrochemiluminescence assays of detect alpha toxin in a biological samples like a serum, and urine, they achieve a detection limits of $1.1 \mathrm{ng} / \mathrm{ml}$ toxin[216].

Epsilon toxin is the third most potent toxin after botulinum and tetanus toxins secreted by Clostridium species, is produced by C. perfringens B and D, and cause lamb dysentery, enterotoxaemia, and fatal disease for domestic animals[10, 205, 217, 218]. Quantification of epsilon toxin in complex matrix like a milk and serum, is possible by mass spectrometry technique developed by Alexandre Seyer et. al. This quantitative assay provides a rapid (few hours) and sensitive detection less than to $5 \mathrm{ng} / \mathrm{mL}$. Because, this method requires high-tech equipment it would be a confirmation method for to complement results obtained in the field[218].

Beta toxin is a virulence determinant in enterotoxaemia and hemorrhagic enterocolitis in the intestine of livestock or humans[219,220]. Beta toxin is extremely sensitive to the action of trypsin and is destroyed quickly in the intestine, for that reason it is possible that a type B infection could be misdiagnosed as type 
$\mathrm{D}[220,221]$. A concluding diagnosis of type $\mathrm{B}$ and $\mathrm{C}$ infections should not be based only on toxin detection and must be diagnosed by pathological, microbiological form too[197, 221].

Jasmina Kircanski et al. propose a capture ELISA for detection and quantitation of beta2-toxin in intestinal contents of neonatal piglet. The limit of detection achieved is $2.0-3.5 \mathrm{ng} / \mathrm{ml}$. Addition of protease inhibitors to the sample prevented degradation of the toxin, nevertheless has to be accompanied by sample processing at low temperature, and acid $\mathrm{pH}[200]$.

Other authors described an ELISA system to detect beta, epsilon and iota toxins with specific antibody to each toxin. This development reported a detection limit of $1 \mathrm{ng} / \mathrm{mL}$ for the beta toxin and the iota toxin, for the epsilon toxin the detection limit was $0.1 \mathrm{ng} / \mathrm{mL}$. The sensitivity of this ELISA is superior by 101000 times than that obtained by lethality dose assay[222].

It is evident that there have not been many advances for the rapid detection of C. perfringens toxins at the protein level.

\section{C. septicum TOXINS}

C. septicum is the main etiological agent of spontaneous myonecrosis, even though infection can also manifest as fatal, necrotizing enterocolitis or distal ileitis[223-229].

It is not part of the normal human intestinal and stool flora $[230,231]$ possibly is an opportunistic pathogen, but is part of the normal gastrointestinal microbiota of many animals[232, 233].

The toxic products of this Clostridium are called alpha, beta, gamma and delta-toxin. Alpha toxin has necrotic, lethal and hemolytic activities, being the most toxic result of C. septicum[234-236].

Diagnosis of spontaneous myonecrosis is difficult and the symptoms are result of an fast systemic infection[237]. Due to the low incidence of this infection, no preventive protocols have been developed, the most prone patients (for example immunosuppressed, with a history of gastric diseases) should undergo a preventive diagnosis, but that has not been implemented yet[227, 229, 238].

The work of Michael J. G. Mallozzi et al.[239] show an excellent review of several aspects of the infection of C. septicum encompassing the diagnosis of the same. In this review it is evident the lack of a fast method and that does not need sophisticated equipment for a quick diagnosis. The most recent advances in the diagnosis of this infection are based on PCR and MALDI TOFF[240-243].

Here is an important niche for the development of rapid alpha toxin detection techniques, since although this infection does not have a high frequency, its outcome is often fatal.

Today, the trend of development of techniques for detecting main clostridials toxins is the use of rapid methods. Mainly, it is based on the need for rapid identification, semi-quantification, for use as diagnostic tool and also useful at industrial level as control of culture process for toxin production. Tendencies of reduction of the use of experimental animals encourage the implementation of these techniques in the industry. In consequence it is crucial to prove the advantages of these rapid methods in order to be implemented over experimental animal use (shorter times, more productive, cost reduction). 


\section{References}

[1] D. J. C. Nigel P. Minton, Ed., Clostridia. New York: Springer Science \& Business Media, 1989.

[2] J. G. Songer, et al., "Clostridial Diseases of Animals," in The Clostridia, ed San Diego: Academic Press, 1997, pp. 153-182.

[3] E. A. Usacheva, et al., "Host response to Clostridium difficile infection: Diagnostics and detection," Journal of Global Antimicrobial Resistance, vol. 7, pp. 93-101, 2016.

[4] M. J. Aldape, et al., "Clostridium sordellii infection: epidemiology, clinical findings, and current perspectives on diagnosis and treatment," Clin Infect Dis, vol. 43, pp. 1436-46, Dec 12006.

[5] S. N. Arseculeratne, et al., "The toxins responsible for the lesions of Clostridium sordelli gas gangrene," J Med Microbiol, vol. 2, pp. 37-53, Feb 1969.

[6] A. Bitti, et al., "A fatal postpartum Clostridium sordellii associated toxic shock syndrome," J Clin Pathol, vol. 50, pp. 259-60, Mar 1997.

[7] J. Glenn Songer, et al., "Clostridium novyi (Myonecrosis, Black Disease, and Bacillary Hemoglobinuria) and Clostridium septicum (Braxy) Infections," in Food Animal Practice (Fifth Edition), ed Saint Louis: W.B. Saunders, 2009, pp. 58-61.

[8] L. Niilo, "Clostridium perfringens in animal disease: a review of current knowledge," Can Vet J, vol. 21, pp. 141-8, May 1980.

[9] L. Niilo, "Clostridium perfringens Type C Enterotoxemia," Can Vet J, vol. 29, pp. 658-64, Aug 1988.

[10] F. A. Uzal, "Diagnosis of Clostridium perfringens intestinal infections in sheep and goats," Anaerobe, vol. 10, pp. 135-43, Apr 2004.

[11] L. Unger-Torroledo, et al., "Lethal toxin of Clostridium sordellii is associated with fatal equine atypical myopathy," Veterinary Microbiology, vol. In Press, Corrected Proof.

[12] F. A. Uzal, et al., "Ulcerative enterocolitis in two goats associated with enterotoxin- and beta2 toxin-positive Clostridium perfringens type D," J Vet Diagn Invest, vol. 20, pp. 668-72, Sep 2008.

[13] C. Rorbye, et al., "Postpartum Clostridium sordellii infection associated with fatal toxic shock syndrome," Acta Obstet Gynecol Scand, vol. 79, pp. 1134-5, Dec 2000.

[14] E. C. D. Todd, "Impact of spoilage and foodborne diseases on national and international economies," International Journal of Food Microbiology, vol. 4, pp. 83-100, 1987. 
[15] Center for Disease Control. Bacterial Diseases Division and Bureau of Laboratories. Enterobacteriology Branch, Botulism in the United States, 1899-1973; handbook for epidemiologists, clinicians, and laboratory workers. Atlanta, Ga.: U.S. Dept. of Health, Education, and Welfare, 1974.

[16] E. C. Mansilla and R. C. Moreno, "Procedimientos en Microbiología Clínica," in Diagnóstico microbiológico de la infección por Clostridium difficile, ed. Madrid: Sociedad Española de Enfermedades Infecciosas y Microbiología Clínica (SEIMC), 2015.

[17] J. G. Songer, "Clostridia as agents of zoonotic disease," Vet Microbiol, vol. 140, pp. 399-404, Jan 27.

[18] P. T. Ting and A. Freiman, "The story of Clostridium botulinum: from food poisoning to Botox," Clin Med (Lond), vol. 4, pp. 258-61, May-Jun 2004.

[19] L. K. Rosow and J. B. Strober, "Infant botulism: review and clinical update," Pediatr Neurol, vol. 52, pp. 487-92, May 2015.

[20] M. Cherington, "Botulism: update and review," Semin Neurol, vol. 24, pp. 155-63, Jun 2004.

[21] C. T. Yeh, et al., "Comparison of immunostrips with mouse bioassay and bacterial culture in detecting botulinum toxins in bottles from suspected Taiwan high-speed rail bomber," Forensic Toxicology, vol. 32, pp. 258-265, 2014.

[22] P. Bossi and F. Bricaire, "[Botulism toxin, bioterrorist weapon]," Presse Med, vol. 32, pp. 463-5, Mar 152003.

[23] S. S. Arnon, et al., "Botulinum toxin as a biological weapon: medical and public health management," JAMA, vol. 285, pp. 1059-70, Feb 282001.

[24] D. M. Gill, "Bacterial toxins: a table of lethal amounts," Microbiol Rev, vol. 46, pp. 86-94, Mar 1982.

[25] M. Shanmugasamy and J. Rajeswar, "Alpha toxin specific PCR for detection of toxigenic strains of Clostridium perfringens in Poultry," Veterinary World, vol. 5, pp. 365-368, 2012.

[26] C. Rodriguez, et al., "Clostridium difficile infection: Early history, diagnosis and molecular strain typing methods," Microbial Pathogenesis, vol. 97, pp. 59-78, 2016.

[27] S. Persson, et al., "New multiplex PCR method for the detection of Clostridium difficile toxin A (tcdA) and toxin B (tcdB) and the binary toxin (cdtA/cdtB) genes applied to a Danish strain collection," Clinical Microbiology and Infection, vol. 14, pp. 1057-1064, 2008.

[28] L. M. Sloan, et al., "Comparison of real-time PCR for detection of the tcdC gene with four toxin immunoassays and culture in diagnosis of Clostridium difficile infection," J Clin Microbiol, vol. 46, pp. 1996-2001, Jun 2008. 
[29] P. Fach, et al., "Development of real-time PCR tests for detecting botulinum neurotoxins A, B, E, F producing Clostridium botulinum, Clostridium baratii and Clostridium butyricum," Journal of Applied Microbiology, vol. 107, pp. 465-473, 2009.

[30] H. A. Behrensdorf-Nicol, et al., "In vitro determination of tetanus toxicity by an endopeptidase assay linked to a ganglioside-binding step," Toxicology in Vitro, vol. 24, pp. 988-994, 2010.

[31] J. J. Schmidt and R. G. Stafford, "Fluorigenic Substrates for the Protease Activities of Botulinum Neurotoxins, Serotypes A, B, and F," Applied and Environmental Microbiology, vol. 69, pp. 297-303, 2003.

[32] P. Fach, et al., "An innovative molecular detection tool for tracking and tracing Clostridium botulinum types A, B, E, F and other botulinum neurotoxin producing Clostridia based on the GeneDisc cycler," International Journal of Food Microbiology, vol. 145, pp. S145-S151, 2011.

[33] B. Hicke, et al., "Automated detection of toxigenic Clostridium difficile in clinical samples: Isothermal tcdB amplification coupled to array-based detection," Journal of Clinical Microbiology, vol. 50, pp. 2681-2687, 2012.

[34] K. K. Hill and T. J. Smith, "Genetic diversity within Clostridium botulinum serotypes, botulinum neurotoxin gene clusters and toxin subtypes," Curr Top Microbiol Immunol, vol. 364, pp. 1-20, 2013.

[35] J. A. Giménez, et al., "Characterization of the neurotoxin isolated from a Clostridium baratii strain implicated in infant botulism," Infection and Immunity, vol. 60, pp. 518-522, 1992.

[36] P. Aureli, et al., "Two Cases of Type E Infant Botulism Caused by Neurotoxigenic Clostridium butyricum in Italy," Journal of Infectious Diseases, vol. 154, pp. 207-211, August 1, 19861986.

[37] A. Goonetilleke and J. B. Harris, "Clostridial neurotoxins," J Neurol Neurosurg Psychiatry, vol. 75 Suppl 3, pp. iii35-9, Sep 2004.

[38] S. Cai, et al., "Botulism diagnostics: from clinical symptoms to in vitro assays," Crit Rev Microbiol, vol. 33, pp. 109-25, Apr-Jun 2007.

[39] H. M. L. Solomon, T.J, In Bacteriological analytical manual, 8th Ed ed. USA: Silver Spring, MD, 2001

[40] J. L. Ferreira, et al., "Detection of preformed type A botulinal toxin in hash brown potatoes by using the mouse bioasssay and a modified ELISA test," J AOAC Int, vol. 84, pp. 1460-4, Sep-Oct 2001.

[41] L. B. Pearce, et al., "Measurement of Botulinum Toxin Activity: Evaluation of the Lethality Assay," Toxicology and Applied Pharmacology, vol. 128, pp. 69-77, 1994/09/01 1994.

[42] D. Sesardic, et al., "Refinement and validation of an alternative bioassay for potency testing of therapeutic botulinum type A toxin," Pharmacol Toxicol, vol. 78, pp. 283-8, May 1996. 
[43] D. A. Boroff and U. Fleck, "Statistical analysis of a rapid in vivo method for the titration of the toxin of Clostridium botulinum," Journal of Bacteriology, vol. 92, pp. 1580-1581, 1966.

[44] Y. Torii, et al., "Quantitative determination of biological activity of botulinum toxins utilizing compound muscle action potentials (CMAP), and comparison of neuromuscular transmission blockage and muscle flaccidity among toxins," Toxicon, vol. 55, pp. 407-14, Feb-Mar 2010.

[45] R. E. Sheridan, et al., "Comparison of in vivo and in vitro mouse bioassays for botulinum toxin antagonists," J Appl Toxicol, vol. 19 Suppl 1, pp. S29-33, Dec 1999.

[46] S. Adler, et al., "The current scientific and legal status of alternative methods to the LD50 test for botulinum neurotoxin potency testing. The report and recommendations of a ZEBET Expert Meeting," Altern Lab Anim, vol. 38, pp. 315-30, Aug 2010.

[47] V. Guglielmo-Viret, et al., "Comparison of electrochemiluminescence assay and ELISA for the detection of Clostridium botulinum type B neurotoxin," Journal of Immunological Methods, vol. 301, pp. 164-172, 2005.

[48] M. Szílagyi, et al., "Development of sensitive colorimetric capture elisas for Clostridium botulinum neurotoxin serotypes A and B," Toxicon, vol. 38, pp. 381-389, 2000.

[49] R. J. Thomas, "Detection of Clostridium botulinum types C and D toxin by ELISA," Australian Veterinary Journal, vol. 68, pp. 111-113, 1991.

[50] G. E. Lewis, et al., "Detection of Clostridium botulinum type $\mathrm{G}$ toxin by enzyme-linked immunosorbent assay," Applied and Environmental Microbiology, vol. 42, pp. 1018-1022, 1981.

[51] T. A. N. Ekong, et al., "Immunological detection of Clostridium botulinum toxin type A in therapeutic preparations," Journal of Immunological Methods, vol. 180, pp. 181-191, 1995/01/01 1995.

[52] C. Shone, et al., "Monoclonal antibody-based immunoassay for type A Clostridium botulinum toxin is comparable to the mouse bioassay," Appl Environ Microbiol, vol. 50, pp. 63-7, Jul 1985.

[53] L. H. Stanker, et al., "Development and partial characterization of high-affinity monoclonal antibodies for botulinum toxin type A and their use in analysis of milk by sandwich ELISA," J Immunol Methods, vol. 336, pp. 1-8, Jul 202008.

[54] H. Ma, et al., "A cyclic peptide-polymer probe for the detection of Clostridium botulinum neurotoxin serotype A," Toxicon, vol. 47, pp. 901-8, Jun 152006.

[55] Y. Zhang, et al., "Simultaneous and sensitive detection of six serotypes of botulinum neurotoxin using enzyme-linked immunosorbent assay-based protein antibody microarrays," Analytical Biochemistry, vol. 430, pp. 185-192, 2012. 
[56] D. J. Chiao, et al., "Monoclonal antibody-based lateral flow assay for detection of botulinum neurotoxin type A," Hybridoma (Larchmt), vol. 27, pp. 31-5, Feb 2008.

[57] S. K. W. Sharma, Richard C., "Methods for Detection of Clostridium botulinum Toxin in Foods," Journal of Food Protection®, vol. 6, pp. 1132-1317, 2005.

[58] S. K. Sharma, et al., "Evaluation of lateral-flow Clostridium botulinum neurotoxin detection kits for food analysis," Appl Environ Microbiol, vol. 71, pp. 3935-41, Jul 2005.

[59] V. R. Rivera, et al., "Rapid detection of Clostridium botulinum toxins A, B, E, and F in clinical samples, selected food matrices, and buffer using paramagnetic bead-based electrochemiluminescence detection," Analytical Biochemistry, vol. 353, pp. 248-256, 2006.

[60] K. E. Sapsford, et al., "A fluorescence detection platform using spatial electroluminescent excitation for measuring botulinum neurotoxin A activity," Biosens Bioelectron, vol. 24, pp. 618-25, Dec 12008 .

[61] J. J. Schmidt, et al., "High-throughput assays for botulinum neurotoxin proteolytic activity: serotypes A, B, D, and F," Anal Biochem, vol. 296, pp. 130-7, Sep 12001.

[62] R. Rasooly, et al., "Detection of botulinum neurotoxin-A activity in food by peptide cleavage assay," Int J Food Microbiol, vol. 126, pp. 135-9, Aug 152008.

[63] M. Wictome, et al., "Development of an In Vitro Bioassay for Clostridium botulinum Type B Neurotoxin in Foods That Is More Sensitive than the Mouse Bioassay," Applied and Environmental Microbiology, vol. 65, pp. 3787-3792, 1999.

[64] M. Dong, et al., "Using fluorescent sensors to detect botulinum neurotoxin activity in vitro and in living cells," Proc Natl Acad Sci U S A, vol. 101, pp. 14701-6, Oct 122004.

[65] J. R. Barr, et al., "Botulinum neurotoxin detection and differentiation by mass spectrometry," Emerg Infect Dis, vol. 11, pp. 1578-83, Oct 2005.

[66] S. R. Kalb, et al., "Detection of Botulinum Neurotoxin A in a Spiked Milk Sample with Subtype Identification through Toxin Proteomics," Analytical Chemistry, vol. 77, pp. 6140-6146, 2005/10/01 2005.

[67] A. E. Boyer, et al., "From the mouse to the mass spectrometer: detection and differentiation of the endoproteinase activities of botulinum neurotoxins A-G by mass spectrometry," Anal Chem, vol. 77, pp. 3916-24, Jul 12005.

[68] S. R. Kalb, et al., "The use of Endopep-MS for the detection of botulinum toxins A, B, E, and F in serum and stool samples," Anal Biochem, vol. 351, pp. 84-92, Apr 12006. 
[69] R. M. Ozanich, et al., "Rapid Multiplexed Flow Cytometric Assay for Botulinum Neurotoxin Detection Using an Automated Fluidic Microbead-Trapping Flow Cell for Enhanced Sensitivity," Analytical Chemistry, vol. 81, pp. 5783-5793, 2009/07/15 2009.

[70] J. W. Grate, et al., "Advances in assays and analytical approaches for botulinum-toxin detection," TrAC Trends in Analytical Chemistry, vol. 29, pp. 1137-1156, 2010.

[71] M. G. Warner, et al., "Quantum dot immunoassays in renewable surface column and 96-well plate formats for the fluorescence detection of Botulinum neurotoxin using high-affinity antibodies," Biosensors \& bioelectronics, vol. 25, pp. 179-184, 2009.

[72] G. P. Anderson and C. R. Taitt, "Amplification of microsphere-based microarrays using catalyzed reporter deposition," Biosens Bioelectron, vol. 24, pp. 324-8, Oct 152008.

[73] J. E. Nuss, et al., "Development of cell-based assays to measure botulinum neurotoxin serotype A activity using cleavage-sensitive antibodies," J Biomol Screen, vol. 15, pp. 42-51, Jan 2010.

[74] B. Thyagarajan, et al., "Capsaicin protects mouse neuromuscular junctions from the neuroparalytic effects of botulinum neurotoxin a," J Pharmacol Exp Ther, vol. 331, pp. 361-71, Nov 2009.

[75] A. Scarlatos, et al., "Cortical networks grown on microelectrode arrays as a biosensor for botulinum toxin," J Food Sci, vol. 73, pp. E129-36, Apr 2008.

[76] G. E. Boldt, et al., "Identification of a botulinum neurotoxin A protease inhibitor displaying efficacy in a cellular model," Chemical Communications, pp. 3063-3065, 2006.

[77] F. S. Ligler, et al., "Array biosensor for detection of toxins," Anal Bioanal Chem, vol. 377, pp. 469-77, Oct 2003.

[78] K. E. Sapsford, et al., "Fluorescence-based array biosensors for detection of biohazards," J Appl Microbiol, vol. 96, pp. 47-58, 2004.

[79] R. A. Ogert, et al., "Detection of Clostridium botulinum toxin A using a fiber optic-based biosensor," Anal Biochem, vol. 205, pp. 306-12, Sep 1992.

[80] P. Kumar, et al., "Detection of botulinum toxin using an evanescent wave immunosensor," Biosens Bioelectron, vol. 9, pp. 57-63, 1994.

[81] K. E. Sapsford, et al., "Biosensor detection of botulinum toxoid A and staphylococcal enterotoxin B in food," Appl Environ Microbiol, vol. 71, pp. 5590-2, Sep 2005.

[82] J. Guo, et al., "A Simple, Rapid and Sensitive FRET Assay for Botulinum Neurotoxin Serotype B Detection," PLoS One, vol. 9, p. e114124, 2014. 
[83] C. Lévêque, et al., "Direct biosensor detection of botulinum neurotoxin endopeptidase activity in sera from patients with type A botulism," Biosensors \& bioelectronics, vol. 57, pp. 207-212, 2014.

[84] J. Halliwell, et al., "Electrochemical impedance spectroscopy biosensor for detection of active botulinum neurotoxin," Sensing and Bio-Sensing Research, vol. 2, pp. 12-15, 2014.

[85] B. G. Dorner, et al., "Biological toxins of potential bioterrorism risk: Current status of detection and identification technology," Trends in Analytical Chemistry, 2016.

[86] S. K. Sharma and R. C. Whiting, "Methods for detection of Clostridium botulinum toxin in foods," J Food Prot, vol. 68, pp. 1256-63, Jun 2005.

[87] P. Čapek and T. J. Dickerson, "Sensing the deadliest toxin: technologies for botulinum neurotoxin detection," Toxins, vol. 2, pp. 24-53, 2010.

[88] T. Grenda, et al., "Methods and difficulties in detection of Clostridium botulinum and its toxins," Polish Journal of Veterinary Sciences, vol. 17, pp. 195-205, 2014.

[89] M. Lindström and H. Korkeala, "Laboratory Diagnostics of Botulism," Clinical Microbiology Reviews, vol. 19, pp. 298-314, 2006.

[90] B. R. Singh, "Botulinum neurotoxin structure, engineering, and novel cellular trafficking and targeting," Neurotox Res, vol. 9, pp. 73-92, Apr 2006.

[91] X. Liu, et al., "Biofunctionalized Gold Nanoparticles for Colorimetric Sensing of Botulinum Neurotoxin A Light Chain," Analytical Chemistry, vol. 86, pp. 2345-2352, 2014/03/04 2014.

[92] Y. Wang, et al., "Time-resolved botulinum neurotoxin A activity monitored using peptidefunctionalized Au nanoparticle energy transfer sensors," Chemical Science, vol. 5, pp. 2651-2656, 2014.

[93] G. B. Stevens, et al., "Bioluminescence assay for the highly sensitive detection of botulinum neurotoxin A activity," Analyst, vol. 138, pp. 6154-6162, 2013.

[94] J. J. Schmidt and K. A. Bostian, "Proteolysis of synthetic peptides by type A botulinum neurotoxin," Journal of Protein Chemistry, vol. 14, pp. 703-708, 1995// 1995.

[95] S. Chen, et al., "Colorimetric detection of active botulinum neurotoxin using $\mathrm{Cu} 2+$ mediated gold nanoparticles agglomeration," Sensors \& Actuators B: Chemical, vol. 235, pp. 563-567, 2016.

[96] E. Wild, et al., "In vitro potency determination of botulinum neurotoxin B based on its receptorbinding and proteolytic characteristics," Toxicology in Vitro, vol. 34, pp. 97-104, 2016.

[97] F. M. Dunning, et al., "Detection of botulinum neurotoxin serotype A, B, and F proteolytic activity in complex matrices with picomolar to femtomolar sensitivity," Appl Environ Microbiol, vol. 78, pp. 7687-97, Nov 2012. 
[98] J. Wang, et al., "Avian eyelid assay, a new diagnostic method for detecting botulinum neurotoxin serotypes A, B and E," Toxicon, vol. 49, pp. 1019-1025, 2007.

[99] A. Afkhami, et al., "Impedimetric immunosensor for the label-free and direct detection of botulinum neurotoxin serotype A using Au nanoparticles/graphene-chitosan composite," Biosensors and Bioelectronics, 2016.

[100] C. Rodriguez, et al., "Clostridium difficile infection: Early history, diagnosis and molecular strain typing methods," Microb Pathog, vol. 97, pp. 59-78, Aug 2016.

[101] S. Fridkin, et al., "Vital signs: improving antibiotic use among hospitalized patients," $M M W R$ Morb Mortal Wkly Rep, vol. 63, pp. 194-200, Mar 072014.

[102] C. Rodriguez, et al., "Clostridium difficile infection in elderly nursing home residents," Anaerobe, vol. 30, pp. 184-7, Dec 2014.

[103] S. Di Bella, et al., "Clostridium difficile Toxins A and B: Insights into Pathogenic Properties and Extraintestinal Effects," Toxins (Basel), vol. 8, May 032016.

[104] M. Delmee, "Laboratory diagnosis of Clostridium difficile disease," Clin Microbiol Infect, vol. 7, pp. 411-6, Aug 2001.

[105] B. E. Laughon, et al., "Enzyme immunoassays for detection of Clostridium difficile toxins A and B in fecal specimens," J Infect Dis, vol. 149, pp. 781-8, May 1984.

[106] T. Planche and M. Wilcox, "Reference assays for Clostridium difficile infection: one or two gold standards?," J Clin Pathol, vol. 64, pp. 1-5, Jan 2011.

[107] T. Planche, et al., "Diagnosis of Clostridium difficile infection by toxin detection kits: a systematic review," Lancet Infect Dis, vol. 8, pp. 777-84, Dec 2008.

[108] T. Planche and M. H. Wilcox, "Diagnostic pitfalls in Clostridium difficile infection," Infect Dis Clin North Am, vol. 29, pp. 63-82, Mar 2015.

[109] L. R. Peterson, et al., "Laboratory testing for Clostridium difficile infection: light at the end of the tunnel," Am J Clin Pathol, vol. 136, pp. 372-80, Sep 2011.

[110] A. V. Kolesnikov, et al., "Ultrasensitive detection of protease activity of anthrax and botulinum toxins by a new PCR-based assay," Pathogens and Disease, vol. 74, pp. ftv112-ftv112, 2016.

[111] L. Alcala-Hernandez, et al., "[Laboratory diagnosis of Clostridium difficile infection]," Enferm Infecc Microbiol Clin, vol. 34, pp. 595-602, Nov 2016.

[112] N. Shetty, et al., "The role of glutamate dehydrogenase for the detection of Clostridium difficile in faecal samples: a meta-analysis," J Hosp Infect, vol. 77, pp. 1-6, Jan 2011. 
[113] K. N. Taylor, et al., "Diagnosis and treatment of Clostridium difficile (C. diff) colitis: Review of the literature and a perspective in gynecologic oncology," Gynecol Oncol, Nov 192016.

[114] M. J. Crobach, et al., "European Society of Clinical Microbiology and Infectious Diseases: update of the diagnostic guidance document for Clostridium difficile infection," Clin Microbiol Infect, vol. 22 Suppl 4, pp. S63-81, Aug 2016.

[115] E. A. Usacheva, et al., "Host response to Clostridium difficile infection: Diagnostics and detection," J Glob Antimicrob Resist, vol. 7, pp. 93-101, Dec 2016.

[116] B. Huang, et al., "Real-Time Cellular Analysis Coupled with a Specimen Enrichment Accurately Detects and Quantifies Clostridium difficile Toxins in Stool," Journal of Clinical Microbiology, vol. 52, pp. 1105-1111, 2014.

[117] L. Song, et al., "Development and validation of digital ELISAs for ultrasensitive detection and quantification of C. difficile toxins in stool," Journal of Clinical Microbiology, July 22, 20152015.

[118] Z. Zhu, et al., "Single domain antibody coated gold nanoparticles as enhancer for Clostridium difficile toxin detection by electrochemical impedance immunosensors," Bioelectrochemistry, vol. 101, pp. 153-8, Feb 2015.

[119] Y.-S. Fang, et al., "Simple approach for ultrasensitive electrochemical immunoassay of Clostridium difficile toxin B detection," Biosensors \& bioelectronics, vol. 53, pp. 238-244, 2014/03// 2014.

[120] A. B. Ryder, et al., "Assessment of Clostridium difficile infections by quantitative detection of tcdB toxin by use of a real-time cell analysis system," J Clin Microbiol, vol. 48, pp. 4129-34, Nov 2010.

[121] J. Islam, et al., "The role of the humoral immune response to Clostridium difficile toxins A and B in susceptibility to C. difficile infection: A case-control study," Anaerobe, vol. 27, pp. 82-86, 2014.

[122] C. von Eichel-Streiber, et al., "Large clostridial cytotoxins--a family of glycosyltransferases modifying small GTP-binding proteins," Trends Microbiol, vol. 4, pp. 375-82, Oct 1996.

[123] C. L. Oakley and G. H. Warrack, "The soluble antigens of Clostridium oedematiens type D (CI. haemolyticum)," J Pathol Bacteriol, vol. 78, pp. 543-51, Oct 1959.

[124] M. Mallozzi, et al., "Spore-forming Bacilli and Clostridia in human disease," Future Microbiology, vol. 5, pp. 1109-1123, 2010/07/01 2010.

[125] C. C. McGuigan, et al., "Lethal outbreak of infection with Clostridium novyi type A and other spore-forming organisms in Scottish injecting drug users," J Med Microbiol, vol. 51, pp. 971-7, Nov 2002. 
[126] H. O. Bagadi and M. M. Sewell, "Experimental studies on infectious necrotic hepatitis (Black Disease) of sheep," Res Vet Sci, vol. 15, pp. 53-61, Jul 1973.

[127] R. D. Gonzales y Tucker and B. Frazee, "View from the front lines: An emergency medicine perspective on clostridial infections in injection drug users," Anaerobe, vol. 30, pp. 108-115, 2014.

[128] J. S. BRAZIER, et al., "Isolation and identification of Clostridium spp. from infections associated with the injection of drugs: experiences of a microbiological investigation team," Journal of Medical Microbiology, vol. 51, pp. 985-989, 2002.

[129] C. Herrera, et al., "Maternal Death Due to Clostridium novyi in an Injection Drug User," Obstet Gynecol, vol. 128, pp. 876-9, Oct 2016.

[130] P. L. Aquino, et al., "Optimization of the Production of Inactivated Clostridium novyi Type B Vaccine Using Computational Intelligence Techniques," Appl Biochem Biotechnol, vol. 179, pp. 895-909, Jul 2016.

[131] K. Amimoto, et al., "The protective effect of Clostridium novyi type B alpha-toxoid against challenge with spores in guinea pigs," J Vet Med Sci, vol. 60, pp. 681-5, Jun 1998.

[132] N. A. Boyd, et al., "The prevention of experimental Clostridium novyi gas gangrene in highvelocity missile wounds by passive immunisation," J Med Microbiol, vol. 5, pp. 459-65, Nov 1972.

[133] D. Pérez-Etcheverry, et al., "A new -toxin monitoring method to optimize production efficiency in industrial cultures of Clostridium novyi B," NISCAIR-CSIR, India, vol. 71, pp. 124-130, Feb-2012 2012.

[134] L. J. REED and H. MUENCH, "A SIMPLE METHOD OF ESTIMATING FIFTY PER CENT ENDPOINTS," American Journal of Epidemiology, vol. 27, pp. 493-497, May 1, 19381938.

[135] E. Pietrzykowski, et al., "Development of an enzyme immunoassay for the detection of Clostridium novyi type B alpha toxin," Biologicals, vol. 19, pp. 293-298, 1991/10/01 1991.

[136] E. Pharmacopoeia, Ed., Vaccinum Clostridii Novyi B ad usum veterinarium. 1984, p.^pp. Pages.

[137] E. Borrmann and F. Schulze, "Detection of Clostridium novyi type B alpha toxin by cell culture systems," FEMS Immunol Med Microbiol, vol. 24, pp. 275-80, Jul 1999.

[138] A. Oksche, et al., "Morphological and biochemical study of cytoskeletal changes in cultured cells after extracellular application of Clostridium novyi alpha-toxin," Infect Immun, vol. 60, pp. 3002-6, Jul 1992.

[139] P. Bette, et al., "Pharmacological and biochemical studies of cytotoxicity of Clostridium novyi type A alpha-toxin," Infection and Immunity, vol. 57, pp. 2507-2513, 1989. 
[140] C. V. E.-S. HELMUT MULLER, 2 AND ERNST HABERMANN1*, "Morphological Changes of Cultured Endothelial Cells after Microinjection of Toxins That Act on the Cytoskeleton," INFECTION AND IMMUNITY,, vol. 60, pp. 3007-3010, July 1992.

[141] R. Al-Mashat and D. Taylor, "Bacteria in enteric lesions of cattle," Veterinary Record, vol. 112, pp. 5-10, January 1, 19831983.

[142] R. Al-Mashat and D. Taylor, "Clostridium sordellii in enteritis in an adult sheep," Veterinary Record, vol. 112, p. 19, January 1, 19831983.

[143] M. Popoff, "Bacteriological examination in enterotoxaemia of sheep and lamb," Veterinary Record, vol. 114, p. 324, March 31, 19841984.

[144] C. J. Lewis and R. D. Naylor, "Sudden death in sheep associated with Clostridium sordellii," Vet Rec, vol. 142, pp. 417-21, Apr 181998.

[145] M. J. Aldape, et al., "A novel murine model of Clostridium sordellii myonecrosis: Insights into the pathogenesis of disease," Anaerobe, vol. 38, pp. 103-10, Apr 2016.

[146] A. Abdulla and L. Yee, "The clinical spectrum of Clostridium sordellii bacteraemia: two case reports and a review of the literature," J Clin Pathol, vol. 53, pp. 709-12, Sep 2000.

[147] E. Meites, et al., "Fatal Clostridium sordellii Infections after Medical Abortions," New England Journal of Medicine, vol. 363, pp. 1382-1383, 2010.

[148] M. Fischer, et al., "Fatal toxic shock syndrome associated with Clostridium sordellii after medical abortion," N Engl J Med, vol. 353, pp. 2352-60, Dec 012005.

[149] C. Sinave, et al., "Toxic shock syndrome due to Clostridium sordellii: a dramatic postpartum and postabortion disease," Clin Infect Dis, vol. 35, pp. 1441-3, Dec 012002.

[150] A. Bitti, et al., "A fatal postpartum Clostridium sordellii associated toxic shock syndrome," Journal of Clinical Pathology, vol. 50, pp. 259-260, 1997.

[151] A. C. Kimura, et al., "Outbreak of necrotizing fasciitis due to Clostridium sordellii among blacktar heroin users," Clin Infect Dis, vol. 38, pp. e87-91, May 012004.

[152] A. S. Tait, et al., "The Large Clostridial Toxins from Clostridium sordellii and C. difficile Repress Glucocorticoid Receptor Activity," Infection and Immunity, vol. 75, pp. 3935-3940, August 1, 20072007.

[153] Y. Hao, et al., "Lethal toxin is a critical determinant of rapid mortality in rodent models of Clostridium sordellii endometritis," Anaerobe, vol. 16, pp. 155-60, Apr 2010. 
[154] K. Amimoto, et al., "Protective effects of clostridium sordellii LT and HT toxoids against challenge with spores in guinea pigs," J Vet Med Sci, vol. 63, pp. 879-83, Aug 2001.

[155] S. Nakamura, et al., "Cytotoxin production by Clostridium sordellii strains," Microbiol Immunol, vol. 27, pp. 495-502, 1983.

[156] D. Pérez-Etcheverry, et al., "Semiquantification of lethal toxin at the bottom of reactors for Clostridium sordellii culture," BTAIJ, vol. 11, pp. 201-209, 2015.

[157] F. De Mattia, et al., "The consistency approach for quality control of vaccines - a strategy to improve quality control and implement 3Rs," Biologicals, vol. 39, pp. 59-65, Jan 2011.

[158] P. A. Nagoba BS, Ed., Medical microbiology NewDelhi Elsevier 2012, p.^pp. Pages.

[159] J. Brostoff, Scadding, G.K., Male, M., Roitt, I.M, Ed., Inmunología Clínica Tomo II. España: Andrómaco, 1994, p.^pp. Pages.

[160] L. F. Duque Sierra, Tétanos: desde la prevención primaria hasta el diagnostico temprano y tratamiento oportuno ante desastres: Universidad CES, Facultad de Medicina, 2012.

[161] T. M. Cook, et al., "Tetanus: a review of the literature," Br J Anaesth, vol. 87, pp. 477-87, Sep 2001.

[162] S. A. Ogunkeyede, Fasunia, A.J., Adeosun, A.A., Lasisi, O.A., "Otogenic tetanus: continuing clinical challenge in the developing country," J Rhinolaryngol-Otologies, vol. 1, pp. 87-90, 20132013.

[163] M. Adeel, et al., "A case of otogenic tetanus," BMJ Case Reports, vol. 2012, July 3, 20122012.

[164] R. Lodha, et al., "Tetanus in immunized children," Indian Pediatr, vol. 37, pp. 223-4, Feb 2000.

[165] M. S. Tullu, et al., "Experience of pediatric tetanus cases from Mumbai," Indian Pediatr, vol. 37 , pp. 765-71, Jul 2000.

[166] G. I. Ugwu and N. E. Okolugbo, "Otogenic tetanus: case series," West Afr J Med, vol. 31, pp. 277-9, Oct-Dec 2012.

[167] E. Prospero, et al., "Epidemiology of tetanus in the Marches Region of Italy, 1992-95," Bulletin of the World Health Organization, vol. 76, pp. 47-54, 1998.

[168] F. L. Ruben, et al., "Antitoxin responses in the elderly to tetanus-diphtheria (TD) immunization," Am J Epidemiol, vol. 108, pp. 145-9, Aug 1978. 
[169] S. Patris, et al., "An experimental design approach to optimize an amperometric immunoassay on a screen printed electrode for Clostridium tetani antibody determination," Biosens Bioelectron, vol. 77, pp. 457-63, Mar 152016.

[170] S. Jain, et al., "Detection of anti-tetanus toxoid antibody on modified polyacrylonitrile fibers," Talanta, vol. 82, pp. 1876-83, Oct 152010.

[171] I. Lukic, et al., "Key protection factors against tetanus: Anti-tetanus toxin antibody affinity and its ability to prevent tetanus toxin - ganglioside interaction," Toxicon, vol. 103, pp. 135-44, Sep 2015.

[172] E. S. Esser, et al., "Tetanus vaccination with a dissolving microneedle patch confers protective immune responses in pregnancy," J Control Release, vol. 236, pp. 47-56, Aug 282016.

[173] H. Wang, et al., "Tetanus Neurotoxin Neutralizing Antibodies Screened from a Human Immune scFv Antibody Phage Display Library," Toxins, vol. 8, p. 266, 2016.

[174] R. H. Fang, et al., "Engineered nanoparticles mimicking cell membranes for toxin neutralization," Adv Drug Deliv Rev, vol. 90, pp. 69-80, Aug 012015.

[175] H. A. Behrensdorf-Nicol, et al., "In vitro determination of tetanus toxicity by an endopeptidase assay linked to a ganglioside-binding step," Toxicol In Vitro, vol. 24, pp. 988-94, Apr 2010.

[176] D. Rustichelli, et al., "Validation of analytical methods in compliance with good manufacturing practice: a practical approach," J Transl Med, vol. 11, p. 197, Aug 272013.

[177] P. Stickings, et al., "Animal Refinement and Reduction: Alternative Approaches for Potency Testing of Diphtheria and Tetanus Vaccines," Procedia in Vaccinology, vol. 5, pp. 200-212, 2011/01/01 2011.

[178] K. Lockyer, et al., "Structural correlates of carrier protein recognition in tetanus toxoidconjugated bacterial polysaccharide vaccines," Vaccine, vol. 33, pp. 1345-52, Mar 102015.

[179] H. B. Modh, et al., "Specific detection of tetanus toxoid using an aptamer-based matrix," $J$ Biotechnol, vol. 238, pp. 15-21, Nov 202016.

[180] I. EuropeanPharmacopoeia, Council of Europe. Tetanus vaccine (adsorbed), monograph 0452

7ed., 2013.

[181] H. A. Behrensdorf-Nicol, et al., "Binding and cleavage (BINACLE) assay for the functional in vitro detection of tetanus toxin: applicability as alternative method for the safety testing of tetanus toxoids during vaccine production," Vaccine, vol. 31, pp. 6247-53, Dec 162013. 
[182] B. Kegel, et al., "An in vitro assay for detection of tetanus neurotoxin activity: Using antibodies for recognizing the proteolytically generated cleavage product," Toxicology in Vitro, vol. 21, pp. 16411649, 2007.

[183] B. G. Stiles, et al., "Clostridium perfringens Epsilon Toxin: A Malevolent Molecule for Animals and Man?," Toxins, vol. 5, pp. 2138-2160, 2013.

[184] S. Yonogi, et al., "BEC, a Novel Enterotoxin of Clostridium perfringens Found in Human Clinical Isolates from Acute Gastroenteritis Outbreaks," Infection and Immunity, vol. 82, pp. 2390-2399, June 1, 20142014.

[185] D. Kitterer, et al., "Gas gangrene caused by clostridium perfringens involving the liver, spleen, and heart in a man 20 years after an orthotopic liver transplant: a case report," Exp Clin Transplant, vol. 12, pp. 165-8, Apr 2014.

[186] D. Kashan, et al., "Uterine Perforation with Intra-Abdominal Clostridium perfringens Gas Gangrene: A Rare and Fatal Infection," J Gynecol Surg, vol. 32, pp. 182-184, Jun 012016.

[187] J. L. McDonel, "Clostridium perfringens toxins (type A, B, C, D, E)," Pharmacology \& Therapeutics, vol. 10, pp. 617-655, 1980/01/01 1980.

[188] W. E. Morris and M. E. Fernández-Miyakawa, "[Toxins of Clostridium perfringens]," Revista Argentina de microbiologia, vol. 41, pp. 251-260, 2009 Oct-Dec 2009.

[189] J. Sakurai, et al., "Major Toxins of Clostridium Perfringens," Journal of Toxicology: Toxin Reviews, vol. 16, pp. 195-214, 1997/01/01 1997.

[190] M. R. Popoff and P. Bouvet, "Clostridial toxins," Future Microbiology, vol. 4, pp. 1021-1064, 2009/10/012009.

[191] E. Goossens, et al., "Toxin-neutralizing antibodies protect against Clostridium perfringensinduced necrosis in an intestinal loop model for bovine necrohemorrhagic enteritis," BMC Veterinary Research, vol. 12, p. 101, 2016.

[192] F. A. Uzal, et al., "Animal models to study the pathogenesis of human and animal Clostridium perfringens infections," Vet Microbiol, vol. 179, pp. 23-33, Aug 312015.

[193] T. Takazawa, et al., "A case of acute onset postoperative gas gangrene caused by Clostridium perfringens," BMC Res Notes, vol. 9, p. 385, Aug 032016.

[194] J. C. Freedman, et al., "Clostridium perfringens Enterotoxin: Action, Genetics, and Translational Applications," Toxins (Basel), vol. 8, Mar 162016.

[195] J. C. Freedman, et al., "Clostridium perfringens Enterotoxin: Action, Genetics, and Translational Applications," Toxins, vol. 8, p. 73, 2016. 
[196] J. A. Smyth, "Pathology and diagnosis of necrotic enteritis: is it clear-cut?," Avian Pathology, vol. 45, pp. 282-287, 2016/05/03 2016.

[197] F. A. Uzal and J. G. Songer, "Diagnosis of Clostridium perfringens intestinal infections in sheep and goats," J Vet Diagn Invest, vol. 20, pp. 253-65, May 2008.

[198] M. R. Goldstein, et al., "Detection and characterization of Clostridium perfringens in the feces of healthy and diarrheic dogs," Canadian Journal of Veterinary Research, vol. 76, pp. 161-165, 2012.

[199] P. R. Berry, et al., "Evaluation of ELISA, RPLA, and Vero cell assays for detecting Clostridium perfringens enterotoxin in faecal specimens," Journal of Clinical Pathology, vol. 41, pp. 458-461, 1988.

[200] J. Kircanski, et al., "Development of an antigen-capture enzyme-linked immunosorbent assay for Clostridium perfringens beta2-toxin in porcine feces and the neonatal piglet intestine," J Vet Diagn Invest, vol. 24, pp. 895-902, Sep 2012.

[201] S. Yonogi, et al., "Development and application of a multiplex PCR assay for detection of the Clostridium perfringens enterotoxin-encoding genes cpe and becAB," J Microbiol Methods, vol. 127, pp. 172-5, Aug 2016.

[202] M. Shanmugasamy and J. Rajeswar, "Alpha toxin specific PCR for detection of toxigenic strains of Clostridium perfringens in Poultry," Vet World, vol. 5, pp. 365-368, 2012.

[203] K. Miyamoto, et al., "Enterotoxigenic Clostridium perfringens: Detection and Identification," Microbes and Environments, vol. 27, pp. 343-349, 2012.

[204] J. G. Songer and R. R. Meer, "Genotyping ofClostridium perfringensby Polymerase Chain Reaction is a Useful Adjunct to Diagnosis of Clostridial Enteric Disease in Animals," Anaerobe, vol. 2, pp. 197-203, 1996/08/01 1996.

[205] R. O. Silva and F. C. Lobato, "Clostridium perfringens: A review of enteric diseases in dogs, cats and wild animals," Anaerobe, vol. 33, pp. 14-7, Jun 2015.

[206] J. Z. Guanghua Wang, Fuying Zheng, Guozhen Lin, Xiaoan Cao, Xiaowei Gong and Changqing Qiu, "Detection of Different Genotypes of Clostridium perfringens in Feces of Healthy Dairy Cattle

from China using Real-Time Duplex PCR Assay " Pak Vet J,, vol. 31, pp. 120-124, 2010.

[207] G. K. Adak, et al., "Trends in indigenous foodborne disease and deaths, England and Wales: 1992 to 2000," Gut, vol. 51, pp. 832-41, Dec 2002.

[208] P. S. Mead, et al., "Food-related illness and death in the United States," Emerging Infectious Diseases, vol. 5, pp. 607-625, Sep-Oct 1999. 
[209] P. Goldwater, "Sudden infant death syndrome: a critical review of approaches to research," Archives of Disease in Childhood, vol. 88, pp. 1095-1100, 2003.

[210] R. D. Naylor, et al., "Detection of Clostridium perfringens alpha toxin by enzyme-linked immunosorbent assay," Res Vet Sci, vol. 63, pp. 101-2, Jul-Aug 1997.

[211] M. L. Hale and B. G. Stiles, "Detection of Clostridium perfringens alpha toxin using a capture antibody ELISA," Toxicon, vol. 37, pp. 471-84, Mar 1999.

[212] S. Kurioka and M. Matsuda, "Phospholipase C assay using p-nitrophenylphosphoryl-choline together with sorbitol and its application to studying the metal and detergent requirement of the enzyme," Anal Biochem, vol. 75, pp. 281-9, Sep 1976.

[213] R. W. Titball, et al., "Molecular cloning and nucleotide sequence of the alpha-toxin (phospholipase C) of Clostridium perfringens," Infect Immun, vol. 57, pp. 367-76, Feb 1989.

[214] M. T. McCourt, et al., "Sandwich ELISA detection of Clostridium perfringens cells and alphatoxin from field cases of necrotic enteritis of poultry," Vet Microbiol, vol. 106, pp. 259-64, Apr 102005.

[215] S. R. Uppalapati, et al., "Generation and characterization of an inter-generic bivalent alpha domain fusion protein alphaCS from Clostridium perfringens and Staphylococcus aureus for concurrent diagnosis and therapeutic applications," J Appl Microbiol, vol. 113, pp. 448-58, Aug 2012.

[216] G. A. Merrill, et al., "A quantitative electrochemiluminescence assay for Clostridium perfringens alpha toxin," Anal Biochem, vol. 357, pp. 181-7, Oct 152006.

[217] G. G. Alves, et al., "Clostridium perfringens epsilon toxin: The third most potent bacterial toxin known," Anaerobe, vol. 30, pp. 102-107, 2014.

[218] A. Seyer, et al., "Rapid quantification of clostridial epsilon toxin in complex food and biological matrixes by immunopurification and ultraperformance liquid chromatography-tandem mass spectrometry," Anal Chem, vol. 84, pp. 5103-9, Jun 052012.

[219] S. Seike, et al., "Role of pannexin 1 in Clostridium perfringens beta-toxin-caused cell death," Biochim Biophys Acta, vol. 1858, pp. 3150-3156, Dec 2016.

[220] M. Nagahama, et al., "Recent Insights into Clostridium perfringens Beta-Toxin," Toxins, vol. 7, pp. 396-406, 2015.

[221] M. Sterne and I. Batty, Pathogenic clostridia. London: Butterworths., 1975.

[222] M. Nagahama, et al., "Enzyme-linked immunosorbent assay for rapid detection of toxins from Clostridium perfringens," FEMS Microbiol Lett, vol. 68, pp. 41-4, Nov 011991. 
[223] P. Valenstein, "The differential diagnosis of clostridial soft tissue infections," Infectious Diseases Newsletter, vol. 12, pp. 76-79, 1993/10/01 1993.

[224] A. King, et al., "Neutropenic enterocolitis due to Clostridium septicum infection," Journal of Clinical Pathology, vol. 37, pp. 335-343, 1984.

[225] E. Chipp, et al., "Successful management of spontaneous Clostridium septicum myonecrosis," $J$ Plast Reconstr Aesthet Surg, vol. 62, pp. e391-3, Oct 2009.

[226] A. Yavuzcan, et al., "Identification of Clostridium septicum in a tubo-ovarian abscess: a rare case and review of the literature," Vojnosanit Pregl, vol. 71, pp. 884-8, Sep 2014.

[227] Y. E. Wu, et al., "Fatal spontaneous Clostridium septicum gas gangrene: a possible association with iatrogenic gastric acid suppression," Arch Pathol Lab Med, vol. 138, pp. 837-41, Jun 2014.

[228] K. Macha, et al., "Ischaemic stroke and Clostridium septicum sepsis and meningitis in a patient with occult colon carcinoma - a case report and review of the literature," BMC Neurology, vol. 16, p. 239, 2016.

[229] A. S. Griffin, et al., "Massive gas gangrene secondary to occult colon carcinoma," Radiol Case Rep, vol. 11, pp. 67-9, Jun 2016.

[230] J. Dylewski and L. Luterman, "Septic arthritis and Clostridium septicum: a clue to colon cancer," CMAJ : Canadian Medical Association Journal, vol. 182, pp. 1446-1447, 2010.

[231] F. A. Kopliku, et al., "Low prevalence of Clostridium septicum fecal carriage in an adult population," Anaerobe, vol. 32, pp. 34-6, Apr 2015.

[232] S. Nakamura, et al., "Taxonomic relationships among Clostridium novyi Types A and B, Clostridium haemolyticum and Clostridium botulinum type C," J Gen Microbiol, vol. 129, pp. 1473-9, May 1983.

[233] J. S. Odani, et al., "Malignant edema in postpartum dairy cattle," J Vet Diagn Invest, vol. 21, pp. 920-4, Nov 2009.

[234] R. K. Tweten, "Clostridium perfringens beta toxin and Clostridium septicum alpha toxin: their mechanisms and possible role in pathogenesis," Vet Microbiol, vol. 82, pp. 1-9, Sep 032001.

[235] C. L. Kennedy, et al., "The alpha-toxin of Clostridium septicum is essential for virulence," Mol Microbiol, vol. 57, pp. 1357-66, Sep 2005.

[236] K. Amimoto, et al., "Genetic variation and cross-reactivity of Clostridium septicum alpha-toxin," Vet Microbiol, vol. 114, pp. 51-9, Apr 162006. 
[237] A. E. Bryant and D. L. Stevens, "Clostridial myonecrosis: new insights in pathogenesis and management," Curr Infect Dis Rep, vol. 12, pp. 383-91, Sep 2010.

[238] S. Nanjappa, et al., "Clostridium septicum Gas Gangrene in Colon Cancer: Importance of Early Diagnosis," Case Rep Infect Dis, vol. 2015, p. 694247, 2015.

[239] M. J. G. Mallozzi and A. E. Clark, "Trusting Your Gut: Diagnosis and Management of <em>Clostridium septicum</em> Infections," Clinical Microbiology Newsletter, vol. 38, pp. 187-191, 2016.

[240] G. Garofolo, et al., "Development of a real time PCR Taqman assay based on the TPI gene for simultaneous identification of Clostridium chauvoei and Clostridium septicum," Journal of microbiological methods, vol. 84, pp. 307-311, 2011/02// 2011.

[241] R. Chean, et al., "Comparing the identification of Clostridium spp. by two Matrix-Assisted Laser Desorption Ionization-Time of Flight (MALDI-TOF) mass spectrometry platforms to 16S rRNA PCR sequencing as a reference standard: a detailed analysis of age of culture and sample preparation," Anaerobe, vol. 30, pp. 85-9, Dec 2014.

[242] A. Grosse-Herrenthey, et al., "Challenging the problem of clostridial identification with matrixassisted laser desorption and ionization-time-of-flight mass spectrometry (MALDI-TOF MS)," Anaerobe, vol. 14, pp. 242-9, Oct 2008.

[243] A. M. Robinson and J. E. Ussher, "Preparation of positive blood cultures for direct MALDI-ToF MS identification," J Microbiol Methods, vol. 127, pp. 74-6, Aug 2016. 